\title{
LA CONFIGURACIÓN ARTÍSTICA DEL MONASTERIO DE LA ENCARNACIÓN DE OSUNA EN LA SEGUNDA MITAD DEL SIGLO XVIII
}

\author{
THE ARTISTIC CONFIGURATION OF THE MONASTERY \\ OF THE INCARNATION IN OSUNA IN THE SECOND \\ HALF OF THE $18^{\mathrm{TH}}$ CENTURY
}

\author{
Antonio Morón CARmona \\ Amigos de los Museos de Osuna. España \\ amoroncarmona@gmail.com
}

\begin{abstract}
El monasterio de la Encarnación de Osuna, de mercedarias descalzas, es uno de los conjuntos monacales artísticamente más completos de los que cuenta esta villa. El presente trabajo revela cómo su aspecto barroco se configura en la segunda mitad del siglo XVIII. Por ello, se darán a conocer las fechas y los costes de los elementos decorativos de su arquitectura (destacan los azulejos de su patio) junto al protagonismo de la comunidad, de las monjas a título personal y de sus familiares en la donación de retablos, esculturas (algunas de procedencia peruana e italianas), pinturas (La Dolorosa de Meneses Osorio) y piezas de artes suntuarias (los atributos de la Virgen de la Merced o el pelícano de plata).

Palabras claves: Monasterio de la Encarnación, Osuna, barroco, donación, coste.
\end{abstract}

The Monastery of the Incarnation in Osuna, which belongs to the Order of Discalced Mercy Sisters, is one of the most complete monastic buildings in artistic terms. This work unveils how its baroque appearance was shaped in the second half of the $18^{\text {th }}$ century. Thus, this work presents the dates and costs of the decorative elements of its architecture, among which the outstanding tiles in the cloister. Additionally, this work analyses the roles of the religious community, the nuns personally and their relatives in the donation of altarpieces, sculptures (some of Peruvian and Italian provenance), paintings (e.g., Meneses Osorio's Lady of Sorrows) and items of sumptuary art (e.g., Our Lady of Mercy's symbols or a silver pelican).

Keywords: Monastery of the Incarnation, Osuna, baroque, donation, cost.

La villa de Osuna es la cabecera principal de las poblaciones que componían el señorío de los Téllez-Girón a la vez que, desde las inquietudes humanistas 
del IV conde de Ureña don Juan Téllez-Girón, se convirtió en el bastión espiritual del ducado por las numerosas fundaciones religiosas que éste patrocinó, sobresaliendo la Iglesia Colegial de Santa María de la Asunción. En consecuencia, Osuna se convirtió en una ciudad monacal en cuyos solares se asentaron diferentes órdenes mendicantes, bien fundadas directamente por el IV conde y sus descendientes o, en otros casos, patrocinadas por ellos cuándo otras familias cercanas a los duques las llevaron a cabo. Los templos de los monasterios serán el único espacio abierto a los laicos ya que el voto de clausura perpetua hasta la muerte en los cenobios femeninos sellará al exterior capillas, oratorios, patios, pasillos y celdas donde se acumularán inmutables el arte de los siglos de la Edad Moderna. La marcha de Osuna de franciscanos, agustinos, mínimos, mercedarios, dominicos, algunos en sus dos ramas, produjo una pérdida material y documental irrepetible que ha dejado un importante vacío en la historia local.

La iniciativa del Patronato de Arte de Osuna, que en 2014 ha conmemorado los cincuenta años de su creación, ha permitido la preservación y recuperación de una parte importante de su patrimonio artístico sacro. En este sentido, su línea editorial inauguró en noviembre de dicho año la serie Fvga Mvndi dedicada a los conventos de clausura, en su primer volumen a las carmelitas descalzas del Monasterio de San Pedro ${ }^{1}$. Unos años antes, en 2010, el mismo Patronato de Arte me encargó la realización del inventario de los bienes artísticos que componen la colección del Museo de Arte Sacro del Monasterio de la Encarnación, regentado por las reverendas madres mercedarias descalzas. La elaboración de dicho inventario se había convertido en una tarea pendiente pese a que su necesidad e importancia eran de sobras conocidas. El trabajo de campo sobre las piezas (titulación, medición, localización, descripción, etc.) se vio completado con la búsqueda de información en el archivo del convento, una fuente necesitada aún de su investigación. Los tomos consultados fueron: "Gastos desde el día 30 de enero de 1746" (hasta mayo de 1804); "Gastos y recibos. Año 1746. Según arreglo del año 1880. Recibo desde el día 30 de enero de 1746" (hasta mayo de 1804) y "Libro de Sacristía de 1880" (que contiene los inventarios de los bienes artísticos reflejando las donaciones, adquisiciones y ventas desde 1783 a 1909). El resultado final de este complejo trabajo ha permitido la redacción de las líneas que a continuación seguirán, en las que se ofrece una aproximación a la configuración artística del monasterio en la segunda mitad del siglo XVIII, desde las obras arquitectónicas que configuran sus dependencias a la dotación de retablos, esculturas, pinturas y piezas de orfebrería. Si bien la autoría de muchas de ellas permanece en el anonimato, destaca el papel patrocinador de devotos, de las monjas y se concretan las circunstancias en que se realizaron.

${ }^{1}$ MORENO DE SOTO, Pedro Jaime (ed.): FUGA MVNDI. Clausuras de Osuna I. El monasterio carmelita de San Pedro. Patronato de Arte-Amigos de los Museos de Osuna. Osuna, 2014. 
La historia de la fundación del cenobio está bien estudiada por el fraile mercedario Cano Manrique ${ }^{2}$. Su origen se encuentra en la persona de doña María Isabel de Sandoval y Padilla, esposa del IV duque de Osuna don Juan Téllez-Girón. doña Juana Lorenza de Sandoval y Roxas, duquesa de Medinasidonia, tía de doña María Isabel de Sandoval, ayudaba con sus bienes a la construcción de conventos a la Orden de la Merced Descalza. Tía y sobrina eran confidentes, por lo que conocía los problemas matrimoniales que le afectaban: no llegaba el ansiado primogénito y eran frecuentes los amoríos del duque fuera de su matrimonio. A su vez, la duquesa consorte contaba con una íntima amiga que era mercedaria descalza, sor Mariana del Espíritu Santo. A su convento en Lora del Río acudió buscando su ayuda espiritual recomendada por su tía, allí vivía sor María de Jesús que, conociendo la desolación de la joven duquesa, prometió ofrecer al Señor toda su vida por la conversión del duque y la llegada de un heredero. En ese momento doña Isabel hizo el voto de fundar en Osuna un convento de religiosas mercedarias descalzas, con el título de la Encarnación de Santa María de Trápana, dando de los bienes de su dote lo necesario para fundarlo. El primogénito, Pedro, nació en Osuna en 1624 pero falleció a los 5 años. Un año después nació Gaspar, el futuro V duque. Las fundadoras del cenobio ursaonés serán, por petición de la duquesa, las referidas sor María de Jesús y sor Mariana del Espíritu Santo. Desde el nuevo convento se mandó a tres religiosas para fundar el de Arcos de la Frontera en 1650 y, en 1665, salieron las hermanas para la fundación del monasterio de Góngora en Madrid.

Los duques y sus sucesores serán los patronos del monasterio por lo que, a continuación de tan dignísimas personalidades, las mercedarias descalzas establecerán relaciones con algunas familias dentro de la órbita de los duques, de modo que apellidos destacados en la ciudad, como Cepeda, Oliva, Tamayo y Govantes, aparecen en los documentos de donación, recibos de censos, ingreso de novicias y testamentos cuyo resultado se materializará, entre otras, en la creación de su colección artística que actualmente se exponen en su templo, coro bajo y salas habilitadas como museo alrededor del patio principal. La IV duquesa de Osuna doña María Isabel de Sandoval donó una escultura de la titular, "imagen de alabastro de Nuestra Señora de Trapana"3 (de un taller trapanés que aún conserva parte de

${ }^{2}$ CANO MANRIQUE, Francisco: Fundación en Osuna del Monasterio de la Encarnación de Trápana de Madres Mercedarias Descalzas (14 de noviembre de 1626). Madrid 2001.

3 AMEO. (Archivo del Monasterio de la Encarnación de Osuna): Memorial de algunos documentos no publicados ni impresos hasta hoy, pertenecientes a antigüedad de esta villa de Osuna, copiados por el Licenciado Don Antonio Valderrama y Varcárcel, presbitero de dicha Villa. Año de 1885. Fuente sin publicar, p. 275. 
su policromía en azul y dorado ${ }^{4}$ ), un frontal y lámpara de plata y un ostensorio de metal dorado con incrustaciones de coral y aplicaciones de esmalte blanco ${ }^{5}$, también de procedencia italiana. Sólo han permanecido la escultura y la custodia de coral; la Virgen de Trapani y el Niño Jesús tienen sendas coronas de plata "que dio Juan Muñoz Bocos a Sor Micaela María de la Santísima Trinidad, su prima”, piezas en forma de gorro cónico invertido con decoración de óvalos y elementos vegetales de tipo carnoso, de mediados del siglo XVII ${ }^{6}$. Sin embargo, la vinculación más significativa entre la casa ducal y las mercedarias la protagoniza una hija del V duque don Gaspar Téllez Girón, que ingresó a los 16 años en 1674, sor Catalina Antonia de la Concepción7, a la que el señor duque regaló "veinte láminas de espejo y pintura guarnecidas". Se conservan en la sala capitular un par de cuadros con marcos de espejo, pequeños grabados en sus esquinas y sólo uno mantiene pintura al centro, que podrían identificarse con lo que ha pervivido de dicha donación. Por su parte, la tradición oral de las monjas atribuye a la generosidad del duque una pareja de pinturas con los bustos de San Pablo y San Ramón Nonato, con voluminosos marcos barrocos dorados.

El lugar donde se asentaron las mercedarias fue el antiguo Hospital de la Encarnación del Hijo de Dios, que fundó en 1549 por el IV conde de Ureña. En los primeros años tras la llegada a Osuna, las monjas reutilizarían las dependencias ya existentes hasta su consolidación definitiva. Pasado algo más de un siglo de su llegada, el monasterio experimenta un incesante proceso constructivo con la renovación de sus dependencias y su dotación artística. En este sentido, entre 1746 y hasta $1803^{8}$ se recoge una amplia relación de gastos por la compra de tejas, ladrillos, vigas y piedra mensualmente, además de "obras" que solo a veces, sucintamente, se mencionan en qué consistían. En 1747 se instaló la campana (la única de su espadaña), dos años más tarde las obras afectaban a la iglesia, al coro alto y al compás y se colocó "la vidriera de la iglesia" (no es ninguna de las actuales, adquiridas entre 1883 y 1892 de Alemania); en 1750 se "componen tejados". A estos gastos hay que sumar, entre 1753 y 1761, varios pagos a la persona de don Juan de Flores, cuyo cargo se especifica como mayordomo. Es éste un dato relevante que descubre uno de los nombres de quien pudo llevar el seguimiento y directrices de las obras. En 1762 se especifica que se produce la colocación de "las cenefas

${ }^{4}$ MORENO DE SOTO, Pedro Jaime y ROMERO TORRES, José Luis: A Imagen y Semejanza, catálogo de la exposición. Osuna, 2014, pp. 82-83.

5 SANZ SERRANO, María Jesús: "La orfebrería en el Monasterio de la Encarnación”, Archivo Hispalense. n 107, 1980, p. 107.

${ }^{6}$ Ibídem, p. 106.

${ }^{7}$ RODRÍGUEZ-BUZÓN CALLE, Manuel: Guía Artística de Osuna. Osuna, 1997, p. 47.

${ }^{8}$ AMEO. Libro de gastos y recibos. Año 1746. Según arreglo del año 1880. Recibo desde el día 30 de enero de 1746", s/f. 
de la iglesia" pagando por ello 1.008 reales, al año siguiente "los suelos" y en enero de 1765 "de la obra de la bóveda" por 2.267 reales. Tanto en el caso de los tejados como en los suelos no se indica qué estancias cubrirían.

La fábrica del templo, con planta de cajón de una sola nave y capilla mayor, estaría próxima su conclusión a mediados del siglo XVIII y las intervenciones estaban encaminadas hacia su decoración. En este sentido, "las cenefas" aluden a las yeserías barrocas que recubren la bóveda de cañón y la cúpula. Esta decoración arranca desde los capiteles compuestos que rematan las pilastras de los muros y la cornisa sobre la que se alza la bóveda. Su ornamentación se basa en la combinación de molduras lisas con formas geométricas dentro de las cuales de desarrolla una fantasía de hojarascas y roleos (Figura 1). La bóveda se divide en dos tramos por tres arcos fajones en cuyos centros aparecen unos florones para el sustento de las lámparas; al centro de los dos grandes tramos unos marcos acogen sendas pinturas sobre lienzos (Santa Ana sosteniendo a la Virgen Niña y al Niño Jesús, apareciendo San José arrodillado a un lado, y la Virgen de la Merced entregando el escapulario a San Pedro Nolasco). Sobre los cuatro lunetos se repiten los escudos policromados de la Merced. Encima de la celosía del coro alto, las yeserías adoptan la forma de medio punto siendo su motivo principal una gran estrella de reminiscencia serliana. La capilla mayor se cubre por una cúpula de media naranja sobre pechinas con los escudos de los fundadores, también policromados. El anillo de la cúpula utiliza las mismas ménsulas que las del arranque de la bóveda y su interior se divide en ochos gajos, dentro de los cuales existen otras tantas ventanas rematadas por veneras y tondos lisos ovalados, alternos en posición vertical u horizontal. Los nervios que la dividen confluyen en la pequeña linterna que cierra este conjunto.

Sin embargo, el espacio del templo necesitó de nuevas actuaciones porque en abril de 1775 se pagan 4.064 reales "por obras en la iglesia y el coro alto", colocándose al año siguiente "los florones de talla para la iglesia" y se doran "las cenefas del coro alto", por lo que se mejoraría y quedaría concluido este espacio de momento. En el caso del coro alto, su techo resulta de la prolongación de la bóveda de la nave aunque aquí solo aparecen las molduras lisas sin ornamentación, no permaneciendo ningún resto de dorado. La única concesión decorativa aquí son sendas hornacinas, junto a la ventana principal, hechas de mampostería muy simples.

A la par que se edifican las zonas donde las mercedarias llevaban a cabo su vida espiritual (templo espléndidamente decorado, coro alto para acoger a toda la comunidad y campana que avisase de la celebración de los cultos), la clausura se organiza de acuerdo a las necesidades de su vida doméstica. Tal es así, que en 1765 se construye la bodega para el almacenamiento de la comida, en 1770 se hace el colmenar (las monjas elaboraban su propia miel), tres años después las pilas, en 1777 se hacen cañerías y la "fuente nueva" y un año después dos hornos de cal. 
En medio de este incesante proceso constructivo se creó un espacio singularísimo en el monasterio y que le otorga una gran fama cuando los turistas lo visitan. En marzo de 1771 se hace un primer pago de 3.280 reales de la "obra del patio" y en diciembre hay un elevadísimo desembolso de 40.000 reales "por las obras del claustro y las escaleras" ". El patio principal tiene planta cuadrada y está porticado con tres arcos de medio punto en cada lateral, sostenidos por columnas de orden toscano en sus dos plantas. El referido año nos acercaría al momento de la colocación de su impresionante zócalo de azulejos, que hasta ahora sólo por razones estilísticas se ubicaba cronológicamente en el último tercio del siglo XVIII ${ }^{10}$ (Figura 2). Estos valiosos y conocidos azulejos conforman una colección diversa en su temática en el que se combinan distintas escenas religiosas y profanas. En las enjutas de los arcos se combinan el escudo de la Merced y el de los duques de Osuna. En las paredes de la galería baja se suceden las escenas del Vía Crucis mientras que el zócalo en sí recoge varias representaciones: los cinco sentidos simbolizados mediante escenas con objetos a los que hacen alusión (olfato al oler una flor, el gusto mediante una mesa repleta de comida o el oído tocando instrumentos musicales), el pasaje del Antiguo Testamento en que Dalila corta el pelo a Sansón, las cuatro estaciones mediante los trabajos agrícolas adecuados de cada una, la propia comunidad de hermanas mercedarias descalzas y, por último, una llamativa representación de la sevillana Alameda de Hércules. Ésta ya presenta su configuración urbanística actual con las dos columnas traídas desde la calle Mármoles con las esculturas de Hércules y Julio César, las otras dos construidas por Cayetano de Acosta y la Cruz del Rodeo. La Alameda refleja la sociedad que existía en la ciudad de Sevilla, un espacio público donde se pueden ver reflejadas las clases más dominantes y otras del pueblo llano: la Iglesia y unos monaguillos, unos sirvientes cogiendo agua, otros con mulos o trabajando en diferentes menesteres, los galanteos de señoritos a damas, los que pasean en sus coches de caballos, los negocios, el juego, una orquesta tocando música, unos niños de clase acomodada volando una cometa, una pelea a esgrima con un herido en el suelo o, simplemente, pláticas de caballeros acomodados. En definitiva, todo se traduce en la vida exterior a la que las religiosas renuncian al jurar clausura perpetua hasta su muerte, por lo que es significativa su colocación en el patio justo enfrente del coro bajo.

A la galería alta se accede mediante una majestuosa doble escalera que también comunica con otro patio. Se articula mediante dos tramos en dirección opuesto que, al unirse en un rellano a la mitad, hace que se combinen la subida y la bajada según a qué parte nos dirijamos. Sus azulejos varían temáticamente

${ }^{9}$ AMEO. Gastos desde el día 30 de enero de 1746, s/f.

10 PLEGUEZUELO HERNÁNDEZ, Alfonso y OLIVER CARLOS, Alberto: "Zócalos y azulejos pintados de los siglos XVII y XVIII en Osuna", Cuadernos de los Amigos de los Museos de Osuna, $\mathrm{n}^{\circ}$ 5, 2003, p. 46. 
entre los de la contrahuella y los del zócalo, de menor altura que el de la planta baja e igual al de la galería superior y del antiguo oratorio (hoy denominado Saleta de los Niños). Se reproducen escenas de cacerías como una de las principales aficiones de la realeza y la nobleza, por lo que en este monasterio adquiere una especial significación por el motivo de su fundación. Estas escenas obedecen a lo que se denomina como montería a la española cuyas características se observan en los elementos que muestran: líneas de puestos con cazadores, utilización de un elevado número de perros, el uso de armas junto a la ballesta y las presas que son jabalíes, lobos, ciervos y conejos. Por otro lado, la presencia del león es inexistente en Andalucía, en todo caso se tratará del gato montés o el lince.

Una vez terminadas las obras del patio principal, para su mejor mantenimiento en 1779 se componen "las latas del claustro", para el desagüe del agua de los tejados, y para el año siguiente "la vela", es decir, el toldo con la que atenuar el fuerte calor estival. A partir de 1783 se realizan otras obras (en el palomar, en la pared de la sacristía, en el molino, colocar dos pilones) cuyos pagos se combinan con los del carpintero "de grueso" y "de fino" y el de "los encaladores" hasta 1804 , por lo que la pintura de las paredes en blanco y la colocación de puertas y ventanas marcaría el final del trabajo de albañilería. Quizá para ello, en 1786, se vuelve a construir otro horno de cal, para continuar con esta labor. Al final de la centuria, vuelve a mencionarse una nueva intervención en el templo con la apertura del comulgatorio en 1794, una minúscula habitación en la capilla mayor, junto a la reja de clausura del coro bajo con el que se conecta mediante una ventanilla, por donde el sacerdote imparte la comunión a las monjas. Este habitáculo cuenta con un altar de mampostería en forma de ménsula pintado en azul con el escudo de la Merced.

Desde mediados del siglo XVIII y hasta el final de la centuria, se observa un desarrollo en la construcción de diferentes zonas del monasterio desde una fase más o menos inicial (compra de los materiales como ladrillos, vigas y tejas) hasta el embellecimiento final (yeserías, azulejos y pintura). Se constata que la fábrica del templo estaba concluida ya que, junto a la referida decoración de las yeserías, hay noticias sobre los retablos que alberga su interior. En concreto, en junio de 1749 (dos años después de la colocación de la campana, simultaneándose con las obras del coro alto y un año antes de los tejados), se recibe de parte del marqués de Casa Tamayo 64 reales para el dorado del retablo del Cristo de la Misericordia ${ }^{11}$, información que se completa con el gasto de 7.393 reales que en 1761 se desembolsa "por dorar los retablos" (el año anterior a la colocación de las yeserías); otra información cuantifica que "el dorado del retablo mayor importó 17.950 reales" $"$. Concretamente, el citado retablo del Cristo de la Misericordia fue donado "por limosna de Don Andrés Tamayo", apellido muy vinculado a las

${ }_{11}$ AMEO. Libro de gastos y recibos... s/f.

12 AMEO. Memorial de algunos documentos..., op. cit., p. 275. 
mercedarias pues de esa familia recibieron, entre 1749 y $1804^{13}$, censos de diferentes cantidades seguramente por la profesión de algún familiar. En la Sala de la Comendadora se encuentra un pequeño retablo de madera dorado, de algo menos de un metro de altura, que puede interpretarse como un boceto del propio retablo del Cristo de la Misericordia. Estos coinciden en la forma de arco de medio punto que tiene el cuerpo central, dentro de él y en un plano más profundo están colocados el Crucificado en el centro y la Virgen Dolorosa y San Juan a derecha e izquierda sobre repisas. Igualmente, en torno a esos años, la imagen del Cristo debió sufrir la intervención que le diera el aspecto con que ha llegado a nuestros días ${ }^{14}$.

Junto a este retablo se sitúa el de San Miguel, que "lo hizo en su trienio de comendadora Sor María Antonia de la Encarnación”, entre 1752 y 1755, mientras que el arcángel fue donado por Pedro Fernández Blasquez ${ }^{15}$. Su escultura es de discreta calidad pero tiene un ingenuo encanto, en madera estofada, vestido como un soldado romano (morrión en la cabeza, coraza y falda), sosteniendo en la mano izquierda la rodela y en la derecha una lanza que clava al demonio, caricaturesca figura con cuerpo de serpiente y cabeza humana con cuernos (Figura 3). La citada sor María Antonia de la Encarnación se descubre como una destacada proveedora artística. Según consta en los inventarios, de las pocas referencias a las pinturas, se dice que hay "un cuadro de Nuestra Señora de la Soledad que dio el oidor Don Gaspar de Albarado a su sobrina Sor Isabel María de Jesús", y otra "un lienzo grande de Nuestra Señora de la Soledad que dio al convento Don Juan Pérez de Vargas para alhaja de su sobrina Sor María de la Encarnación" "16. Actualmente no existe otro lienzo con el tema de la Virgen Dolorosa o de la Soledad que el ejecutado por Francisco Meneses Osorio en 1703, discípulo de Murillo, la obra pictórica más relevantes del monasterio. El hecho de que ambas descripciones se distingan al utilizar el adjetivo "grande" hace pensar que, por sus dimensiones, se corresponda con el de Meneses Osorio. Al consultar el Libro de profesiones de las religiosas se lee que en 1716, unos años después de la realización del cuadro pero antes de la muerte del pintor, profesó sor María Antonia de la Encarnación. Junto a ello hay que considerar el hecho de que el padre del pintor fuera vecino de Osuna, tal y como él mismo afirma en el acta de fundación de una capellanía que hizo en favor de su hijo ${ }^{17}$. Por ello, quizá la obra fuera encargada por don Juan

${ }_{13}$ AMEO. Libro de gastos y recibos... s/f.

${ }^{14}$ DOMÍNGUEZ GÓMEZ, Benjamín: "Intervención sobre la imagen del Santísimo Cristo de la Misericordia. Convento de la Encarnación. Mercedarias Descalzas", Cuaderno de los Amigos de los Museos de Osuna, nº 11, 2009, pp. 93-95.

15 AMEO. Libro de Sacristía de 1880, s/f.

${ }^{16}$ AMEO. Libro de Sacristía... op. cit., s/f.

17 SERRA GIRÁlDEZ, Sofia: Francisco Meneses Osorio, discípulo de Murillo. Sevilla, 1990. 
Pérez de Vargas y finalmente donada al monasterio donde había ingresado su sobrina, fallecida en 1771 .

Continúan los gastos para la adquisición de un patrimonio artístico relacionado con el culto a la Virgen María y los santos, afortunadamente en gran parte conservado: en 1759 se adquieren "imágenes" y en 1760 el "vestido de la Virgen de la Merced". Por ser la patrona y la gran devoción de las monjas, a la Virgen de la Merced (escultura que preside el coro bajo) se le adquirirán destacadas piezas por su suntuosidad y riqueza. Alcanza un metro y medio de altura, es de candelero para vestir con la cabeza y una larga cabellera talladas, en posición frontal con la mirada baja, y las manos extendidas (Figura 4). Su variado ajuar textil, en tisú y sedas brocadas y bordadas, se completa con la espectacular corona cuyo coste, además de un rostrillo y anillos que no existen actualmente, ascendió a 2.366 reales en $1771^{18}$. Está labrada en plata dorada, consta de canasto del que parten cuatro imperiales que confluyen en un orbe culminado en una cruz latina. Se rodea de ráfaga lobulada con grupos de rayos plisados combinados con ramilletes de flores. Su ornamentación se enriquece con perlas, esmeraldas y amatistas. Cuenta con la marca AV por lo que se atribuye al platero Ávila ${ }^{19}$ (Figura 5). Al año siguiente se pagan 2.000 reales "de los lazos de esmeraldas de Nuestra Santísima Madre" (piezas que tampoco se conservan) y 2.532 reales por el escapulario, una pieza de filigrana y joyería con dos largas cadenas que pende de la mano de la Virgen. En él se muestran el escudo de la Merced y una $\mathrm{S}$ atravesada por un clavo, también decorado con multitud de perlas, esmeraldas y amatistas. Este conjunto se completa con el escudo pectoral, que si bien no se ha encontrado ninguna mención a él, responde al mismo momento y estilo. Reproduce el anagrama del Ave María en filigrana de oro y cuajado de perlas, en su centro aparece un águila bicéfala coronada, con los ojos de esmeraldas, con el escudo de la Merced de brillantes en su pecho. El último encargo para la Virgen de la Merced es el de "las andas" en 1773 por 3.922 reales. Constaban de "veinte cañones de plata y cuatro bases de lo mismo, cuatro ramitos redondos con sus jarritos y cuatro llanos con sus canastillas todo de plata" que se completaban con las "caídas y cielo de terciopelo carmesí con sus franjas y flecos de oro". Se trataría de un antecedente del paso de palio sevillano, unas parihuelas quizá portadas por el exterior en las que la mencionada Virgen procesionaría en la fiesta de su onomástica, para ello usaría las dos puertas del templo y seguramente subiría hacia la cercana Colegiata de la Asunción. Su tamaño sería reducido, de planta cuadrada con cuatro varales en las esquinas que sostendría el palio carmesí decorado con pasamanerías y flecos en hilo de oro. El coqueto conjunto se completaba con un exorno floral también en plata,

18 AMEO. Libro de gastos y recibos... s/f.

19 MEJÍAS ÁLVAREZ, María Jesús: "Aproximación a las marcas de joyería española del siglo XVIII", San Eloy 2004, Murcia, 2004, p. 292. SANZ SERRANO, María Jesús: "La orfebrería en...", op. cit., p. 108. 
distribuido en jarras y "canastillas" de diferentes tamaños. Desafortunadamente, las dificultades económicas de las mercedarias obligaron su venta en 1824 "para las urgencias y manutención de la comunidad”. El volumen económico que manejaban las monjas mercedarias se hace especialmente elevado en la década de los setenta del siglo XVIII puesto que hacen frente a la contratación de estas importantes piezas de las artes suntuarias a la vez de la construcción del patio, la escalera y la colocación de sus azulejos.

Volviendo al templo, su mobiliario se venía completando desde 1746 con la adquisición de tres sillones de tipo fraileros (actualmente expuestos en la Sala de la Comendadora) a los que las monjas le bordaron en su respaldo el escudo de la Merced. En 1765 la sacristía se dotó de dos suntuosos espejos, con marcos barrocos de madera dorada, y un dosel a juego para cobijar el Crucificado que había donado el padre general Miguel Ramón de San José, talla que ha perdido parte de su policromía original. Las puertas del templo se colocaron en 1775 por 3.724 reales y, dos años más tarde, se mandaron construir las quince bancas para los fieles, por 5.064 reales, que permanecen en uso a día de hoy. Entre octubre de 1777 y septiembre de $1782^{20}$, las monjas mercedarias le tienen alquilada una casa al doctor Francisco de Luna, quién donaría en ese tiempo la imagen de San José. Esta escultura de talla completa, en madera estofada, muestra un movimiento contenido y se caracteriza por llevar al Niño Jesús dormido reposando sobre su hombro. Su retablo, frente al de San Miguel, fue costeado "por el devoto Don José de Cepeda" 21 al igual que la tribuna desde donde veían la misa las monjas enfermas, elemento éste último que hay que añadir a las numerosas donaciones que dejó en Osuna $^{22}$. Sin embargo, actualmente el San José se ubica en el retablo consagrado a la Encarnación ${ }^{23}$, situado frente al coro bajo.

Los gastos también se dirigen a dotarse del ajuar necesario para la celebración del Triduo Pascual. De este modo, en 1773 se destinan 3.034 reales por "el pelícano y la hechura de la cruz" y 331 reales por el tenebrario. El primero es un sagrario de plata labrada, anónimo, de sesenta centímetro de altura con dos cuerpos. Uno, como peana de perfil bulboso con cartelas en forma de rocallas en sus frentes, que reproducen motivos relacionados con su finalidad y con el nombre del monasterio: el cordero eucarístico sobre el libro de los siete sellos, espigas de

${ }^{20}$ AMEO. Libro de gastos y recibos... s/f.

${ }^{21}$ AMEO. Memorial de algunos documentos..., op. cit., p. 278.

${ }^{22}$ MORENO ORTEGA, Rosario: "El legado de Don José Cepeda y Toro", Cuaderno de los Amigos de los Museos de Osuna, n 14, 2012, pp. 26-31. MORENO DE SOTO, Pedro Jaime: "Los Cepeda en su esfera simbólica. Santa Teresa, San Francisco y la Santa Vera Cruz de Osuna”, Cuaderno de los Amigos de los Museos de Osuna, n 11, 2009, pp. 51-56.

${ }^{23}$ MORÓN CARMONA, Antonio: "El Misterio de la Encarnación de Nuestro Señor en el Monasterio de la Encarnación de Osuna", Cuaderno de los Amigos de los Museos de Osuna, $\mathrm{n}^{\mathrm{o}} 14,2012$, p. 72. 
trigo y racimo de uva, el escudo de la Merced y la Anunciación de la Virgen María. El otro es el pelícano en sí, que arquea su cuello para, con el pico, rasgarse el pecho y dar de comer a sus tres polluelos. Los ojos del ave principal son de rubíes y su espalda se abre para reservar la Hostia en su interior. La cruz puede corresponderse con la de altar, de sesenta y cinco centímetros, marcada tres veces con el apellido Bravo. Fue labrada en plata por el platero Juan Nicolás Bravo ${ }^{24}$ a dos caras sobre una peana oval con cuatro cartelas donde se reproducen las Arma Christi y el escudo de la Merced. Sobre su superficie se desarrolla una decoración de rocallas y de hojarascas (Figura 6). El tenebrario, por su parte, con algo más de dos metros y medio de altura, tiene tres pies donde vuelve a utilizarse la figura del pelícano, fuste como un estípite y el cuerpo superior que adopta la forma triangular para poner quince velas, con el escudo mercedario al centro. Se doró un par de años más tarde por 900 reales.

Para el anteriormente citado retablo de la Encarnación, el mayor tamaño del templo después del principal, se ejecutaron las imágenes de San Pedro Pascual y la Beata Mariana de Jesús en septiembre de $1783^{25}$ (Figuras 7 y 8). Sendas esculturas de madera tallada y estofada, fueron patrocinadas por Sor María Josefa de San Ramón por un valor de 772 reales, cuantía que englobaba su hechura, traslado y colocación. El mercedario San Pedro Pascual aparece vestido como Obispo, pues lo fue de Jaén, adelantado la pierna izquierda, con el cuerpo girado y los brazos extendidos hacia ese mismo lado mientras que la cabeza está orientada hacia la derecha y algo elevada. Un matiz más para acentuar su movimiento es el vuelo del roquete, que como una tela suave y ligera se mueve a la derecha tras el ímpetu de adelantar la pierna contraria. Muestra su cabeza mitrada, un cuchillo clavado en el cuello (por haber sido decapitado) y una pluma en la mano derecha. Faltaría un libro en su mano pues se le atribuye la autoría, en catalán, del Catecisme del bisbe de Jaén. El cuchillo y la pluma son de plata, donados en 1786 por la citada sor María Josefa de San Ramón, habiéndose perdido un pectoral del mismo material. Por su parte, la imagen de la Beata Mariana de Jesús, adelanta la pierna derecha y recoge sobre ese brazo el vuelo de su capa. Este movimiento queda compensado por la serenidad e íntima espiritualidad que trasmite. A ello contribuye la belleza de su rostro joven, con expresión dulce e idealizada respecto a las máscaras funerarias que se sacaron el día de su muerte; y la recogida posición de sus manos cruzadas sobre el pecho. Sobre su cabeza aparece tallada la corona de espinas y entre sus manos sostenía una cruz en plata con los atributos de la Pasión, no conservada, donada también sor María Josefa de San

${ }^{24}$ SANTOS MÁRQUEZ, Antonio: "Aproximación al Arte de la Platería en Osuna”, San Eloy 2003, Murcia, 2003, p. 560.

25 AMEO. Libro de gastos y recibos... s/f . 
Ramón. Su aureola, bonita pieza de plata repujada con el escudo de la Merced y elementos florales ${ }^{26}$, fue dada por sor Mariana de la Merced.

La llegada de estas efigies se produjo el mismo año en que el papa Pío VI declaró beata a la monja mercedaria; en el archivo conventual se conservan sendas copias del acta de beatificación, reproducidas por la Reverenda y Apostólica Cámara Tipográfica de Roma. En abril de 1784 se celebró por primera vez en el monasterio la festividad de la Beata Mariana de Jesús con su nueva escultura por lo que, siguiendo el listado de gastos de esa jornada, sabemos en qué consistió su celebración: "los que compusieron la iglesia" fueron los encargados de adornar y montar un altar en honor de la beata, para lo que se alquiló cera que, junto al pago del sermón, sumaron 235 reales; la música estuvo presente con un concierto en la víspera y en el propio día de la fiesta, tocaron "los clarines del Regimiento" y se pagó hasta "al campanero de la Colegial" para su repique. No faltó la parte gastronómica con bizcochos y dulces (algunos de chocolate) "para la comunidady combite de dicho día". En 1785 llegó el pequeño relicario de plata con forma de ostensorio "de la carne de Nuestra Beata M. Mariana de Jesús y relicario de su ropa", que costó 234 reales, incrementándose así su devoción.

El papel de las monjas mercedarias es crucial en la conformación artística del monasterio como ya se ha mencionado, especialmente en escultura de pequeño formato. Al patrocinio de sor María Josefa de San Ramón se debe, también, el San Miguel niño y el Sagrado Corazón de Jesús niño, en el tercer cuarto del siglo XVIII. Ambas son destacables porque su origen traspasan las fronteras peninsulares: la primera se realizó en un taller peruano, en madera policromada con atributos de plata de José Rodríguez ${ }^{27}$, y la segunda en un taller napolitano en cera, corcho y telas encoladas ${ }^{28}$. Al amplio listado de monjas que han vivido en su clausura, cabría citarse a sor Bárbara Josefa de Jesús María, quién donó la delicada de escultura de San José ubicada en la centuria dieciochesca en el oratorio y actualmente en el coro bajo; Sor Mariana de la Santísima Trinidad con la de San Francisco de Paula antes en el coro alto y ahora en el bajo; sor Josefa de la Concepción y el Niño Jesús del Mayor Dolor, del taller antequerano de Diego Márquez ${ }^{29}$; sor Isabel de la Asunción y su Inmaculada Concepción también mudada del oratorio al coro bajo; sor Josefa Isabel de Dolores con la pequeña Virgen del Rosario expuesta en la Saleta de los Niños; sor María Josefa de San Cayetano con la Virgen de la Merced Comendadora, anónima granadina con

\footnotetext{
${ }^{26}$ SANZ SERRANO, María Jesús: "La orfebrería en...”, op. cit., pp. 108-109.

${ }^{27}$ SANTOS MÁRQUEZ, Antonio: Ibídem, p. 109.

${ }^{28}$ MORENO DE SOTO, Pedro Jaime y ROMERO TORRES, José Luis: A Imagen y..., p. 72.

${ }_{29}$ Ibídem, p. 67.
} 
corona de plata de Vicente Bravo ${ }^{30}$; y familiares como don Miguel Ortega quién donó a la madre sor Margarita de la Natividad la bella escultura de San Pascual Bailón y la del Niño Jesús Circuncidado y Príncipe de la Paz.

A lo largo de estas líneas se ha expuesto el complejo proceso en el que, en la segunda mitad del siglo XVIII, se alterna la construcción de los diferentes espacios del monasterio de la Encarnación con su embellecimiento (yeserías, azulejos, encalado) y dotación artística de su interior (retablos, esculturas y piezas suntuarias para el culto sagrado), bien sea mediante compra o bien como donación de las monjas o sus familiares. Para finalizar, hay que referirse al modo de pago de los gastos, que también se había ido anotando en los libros de la comunidad sin especificar el concepto ni el destinatario. Desde el último tercio de la centuria, desde 1775 hasta 1795, los VIII y XI duques de Osuna, don Pedro III y don Pedro IV Téllez-Girón, se hacen cargo de parte de los gastos "limosna que dio Su Excelencia para la obra", "para la pared de la sacristía" con diversas cantidades $(300,2.000,2.000,1.200$ y 1.000 reales) junto a otros de tipo ordinario como la cera del Monumento o la nieve para el verano. Sí se recoge el nombre de otra benefactora, doña Isabel Vela de Almazán Barona, quién se ocupó de parte de la financiación de las diversas obras desde 1789 hasta 1798, adelantando dinero que posteriormente se le fue devolviendo. La buena disposición de esta señora se culminó con la escultura del Cristo del Amparo, legado testamentariamente hecho en $1794^{31}$. El crucificado se encuentra enmarcado en un dosel con pabellón superior, para ser apoyado sobre una superficie plana, aunque se encuentra colgado del muro del Evangelio del templo. Jesucristo aparece muerto sobre una cruz arbórea de color verdoso y cuenta con potencias (marcadas con el apellido Rubio, correspondiente al platero ursaonés Mariano Rubio ${ }^{32}$ ) y corona de espinas de plata y tres clavos en forma de rosa en plata con un rubí al centro.

Otra fuente importante de financiación fueron los bienes de las mercedarias, en efectivo o en propiedades inmuebles, de los que obtenían la liquidez necesaria "con licencia de Nuestro Padre Provincial". Desde 1791 hasta 1804 sacaron de su depósito grandes cantidades $(11.000,20.000,4.400,14.000,4.334$ reales) que se alternaban con la venta de tierras ( 857 pies de olivar y 47 matas que a varios precios sumaron 71.668 reales, "por la venta de un censo que poseíamos en la Puebla del Saucejo que vendimos a un acreedor 6102 reales" y por hasta una docena de "tierras vendidas para sembrar" de distintas extensiones). Por último, las mismas

${ }^{30}$ Ibíd p. 34; MORÓN CARMONA, Antonio: "Aportación de nuevas obras a la producción de los plateros ursaonenses de los siglos XVIII y XIX", Cuaderno de los Amigos de los Museos de Osuna, n 16, 2014, p. 105.

${ }^{31}$ GUTIÉRREZ NÚÑEZ, Francisco Javier: "Una "visión cultural” de los testamentos ursaonenses de finales del siglo XVIII", Apuntes 2, n 4, 1996, p 88.

${ }^{32}$ MORÓN CARMONA, Antonio: "Platería y joyería", en FUGA MVNDI. Clausuras de Osuna I. El monasterio carmelita de San Pedro. Osuna, 2014, pp. 200-201. 
monjas tuvieron que aportar de sus propios bienes lo necesario para el pago de sus innumerables gastos, de modo que en abril de 1800 se termina de pagar a la madre comendadora, la espléndida sor María Josefa de San Ramón, "lo que de sus rentas debía este convento, 3415 reales".

Fecha de recepción: 22 de julio de 2015.

Fecha de aceptación: 20 de noviembre de 2015. 


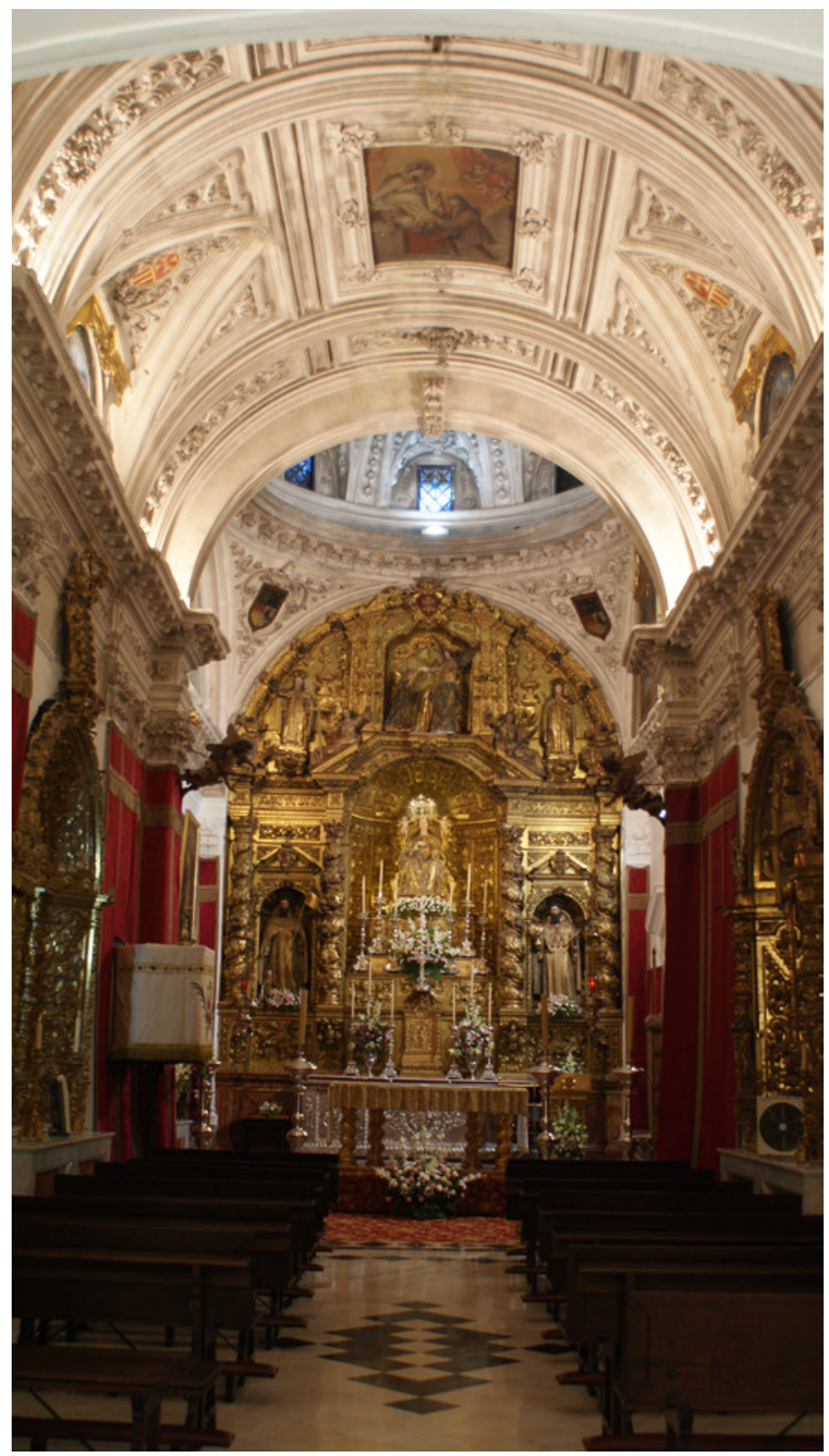

Figura 1. Interior del templo del monasterio de la Encarnación con decoración barroca de la segunda mitad del siglo XVIII. Fotografía: Pedro Jaime Moreno de Soto. 


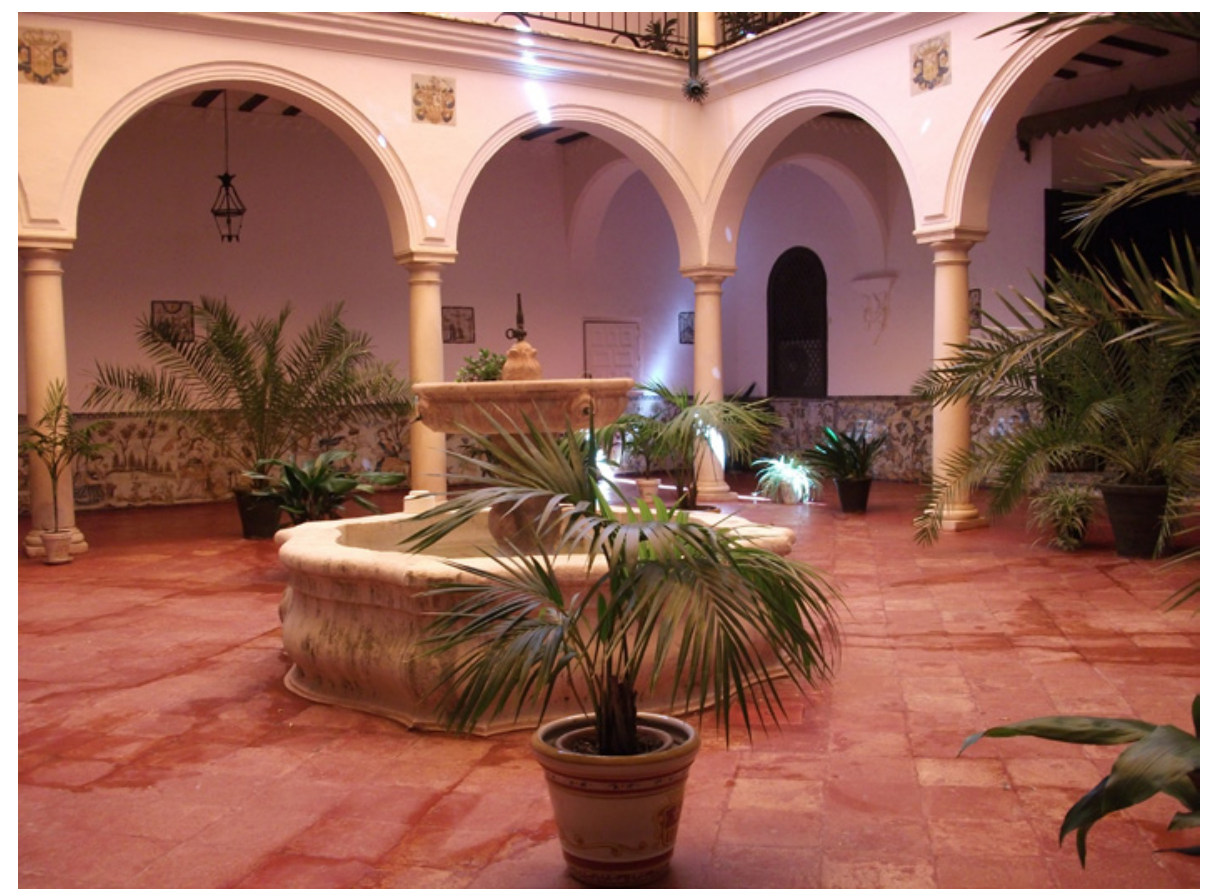

Figura 2. Vista parcial del patio principal decorado con azulejos de 1771. Fotografía: Pedro Jaime Moreno de Soto. 


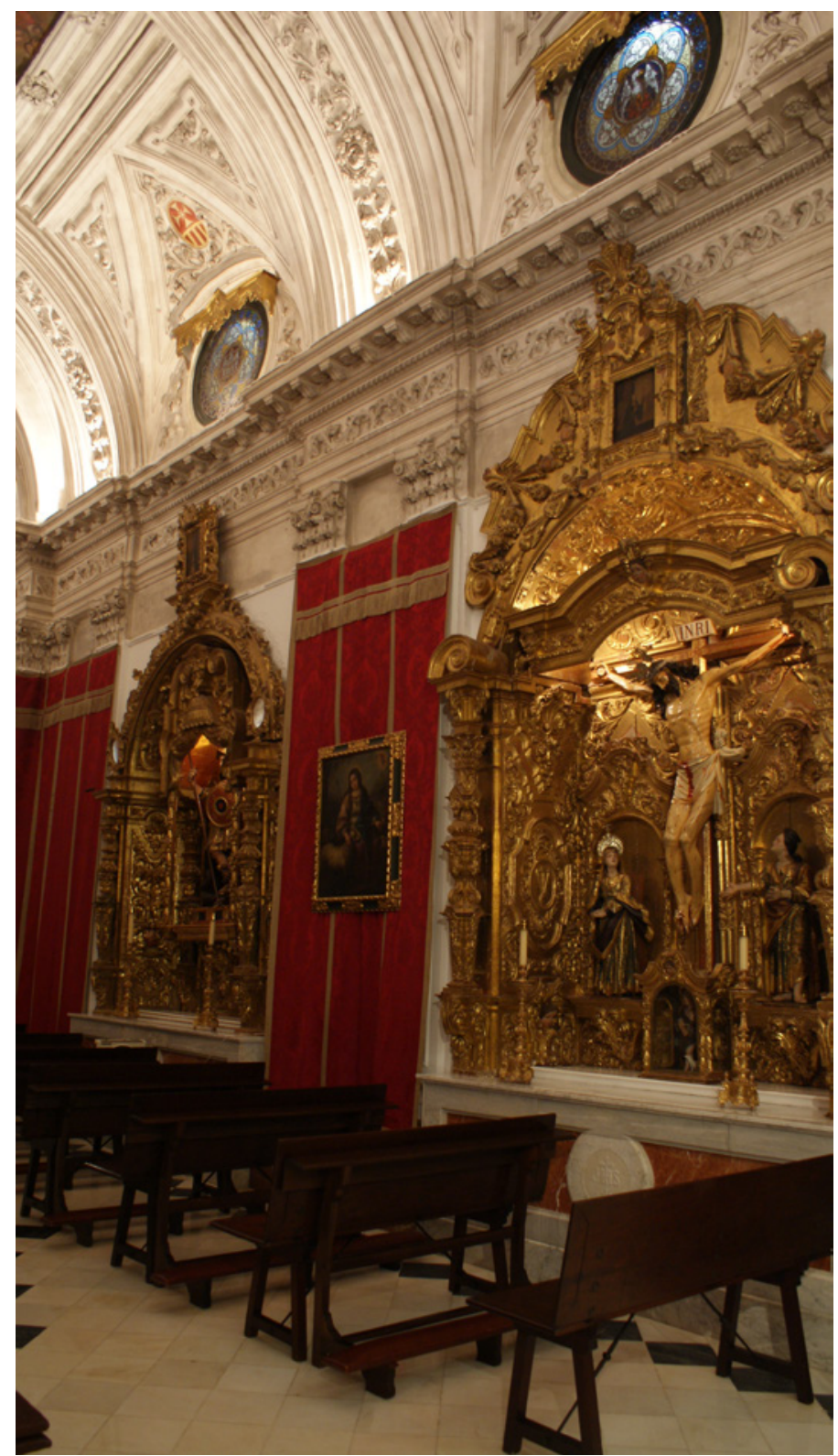

Figura 3. Retablos del Cristo de la Misericordia y de San Miguel Arcángel donados por don Andrés Tamayo y sor María Antonia de la Encarnación, respectivamente. Fotografía: Pedro Jaime Moreno de Soto. 


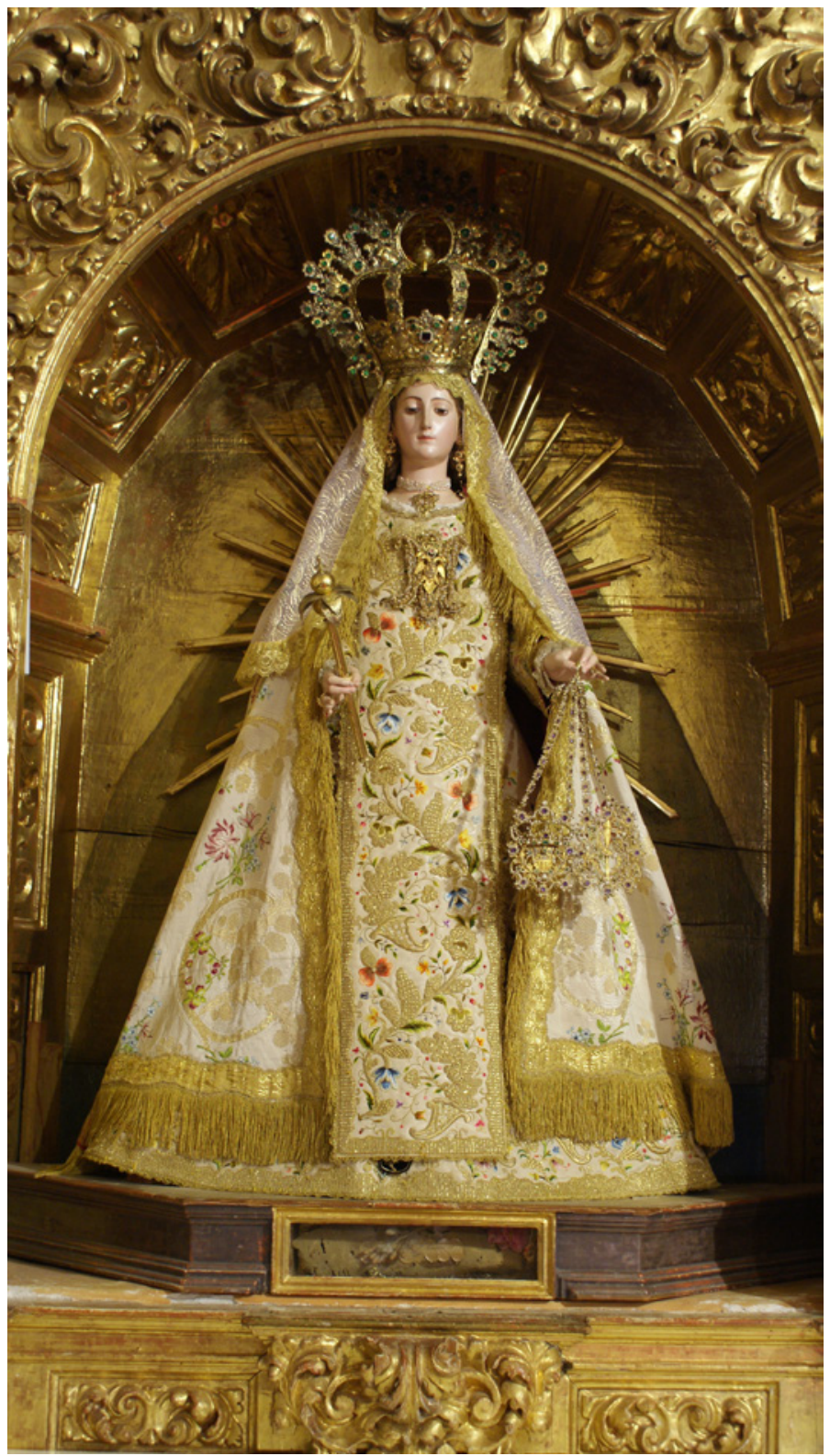

Figura 4. Escultura de la Virgen de la Merced que preside el coro bajo, con corona y escapulario adquiridos en 1771 y 1772. Fotografía: Pedro Jaime Moreno de Soto. 


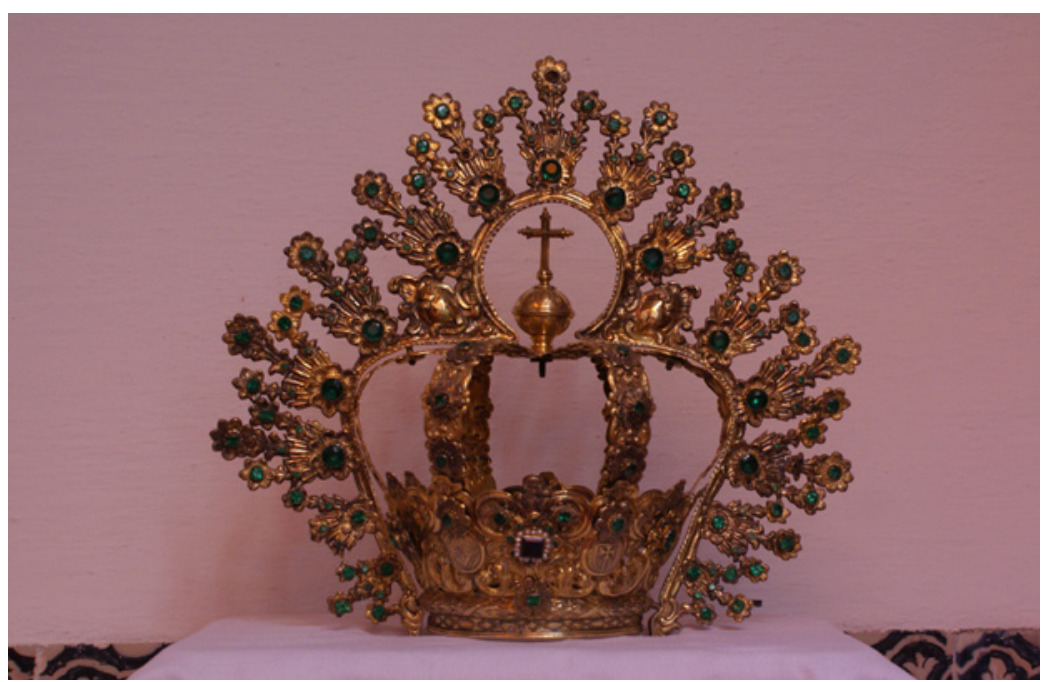

Figura 5. Corona de plata dorada decorada con esmeraldas, atribuida al platero Ávila y adquirida en 1771 por 2.366 reales. Fotografía:

Pedro Jaime Moreno de Soto.

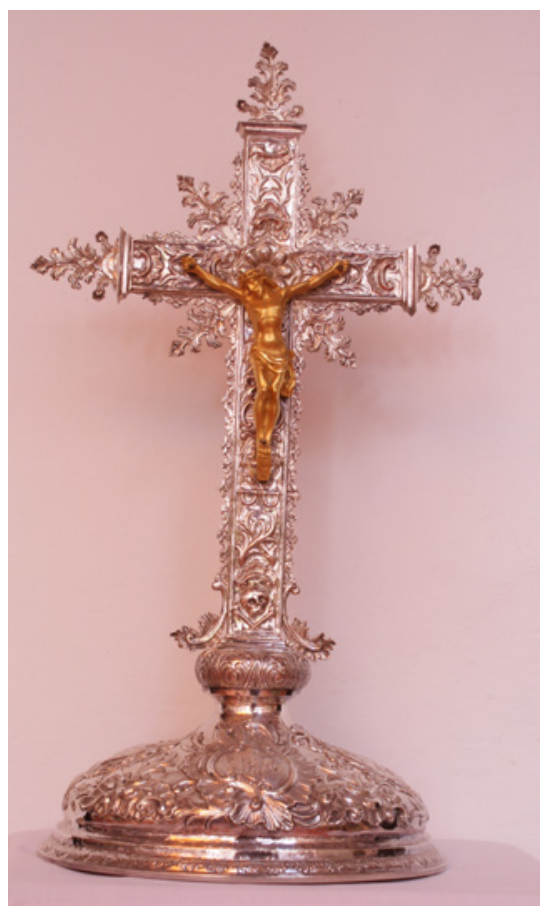

Figura 6. Cruz de plata de Juan Nicolás Bravo, de estilo rococó, adquirida en 1773. Fotografía: Pedro Jaime Moreno de Soto. 


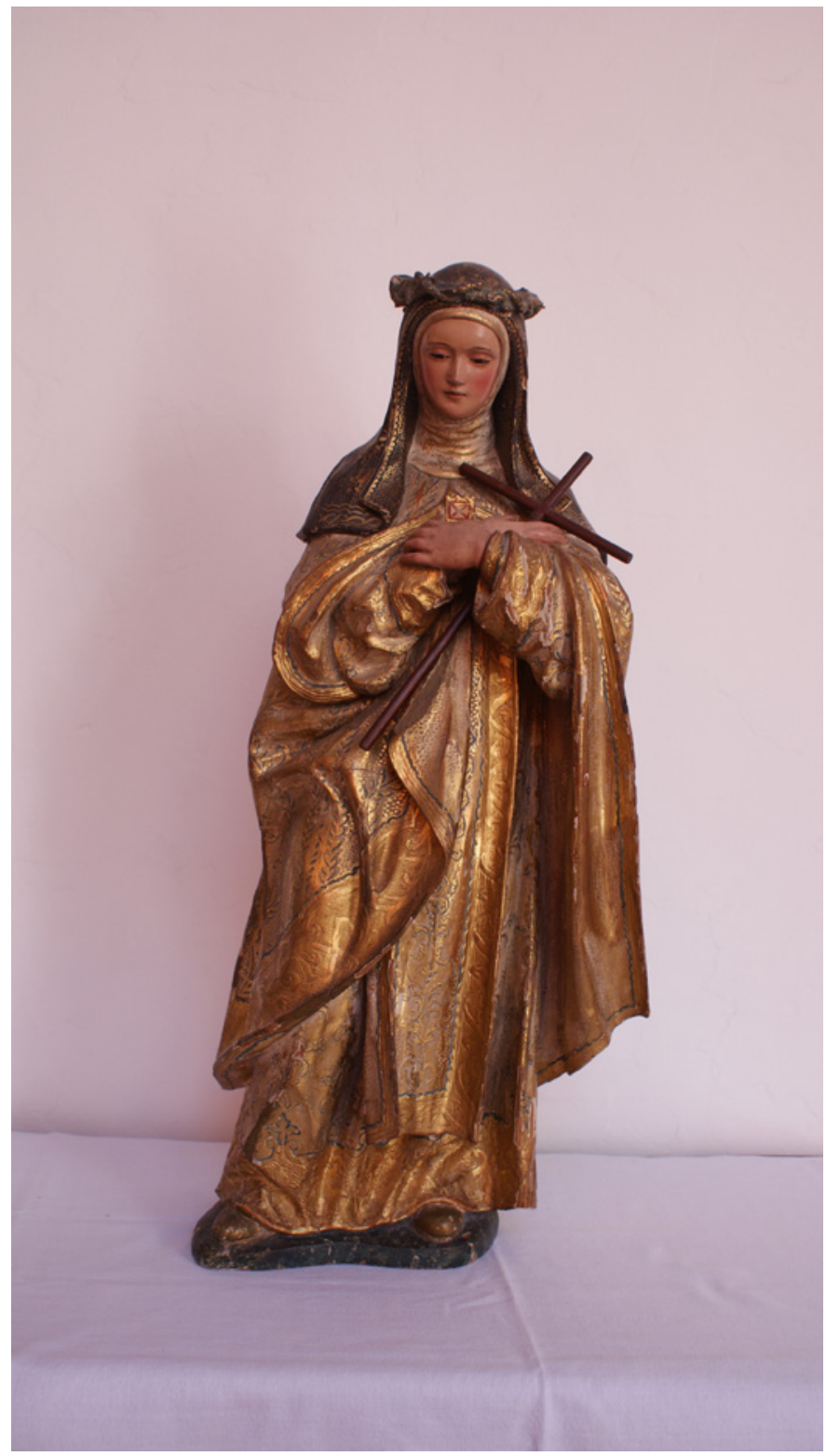

Figura 7. Escultura de la Beata Mariana de Jesús donada por sor María Josefa de San Ramón en 1783. Fotografía: Pedro Jaime Moreno de Soto. 


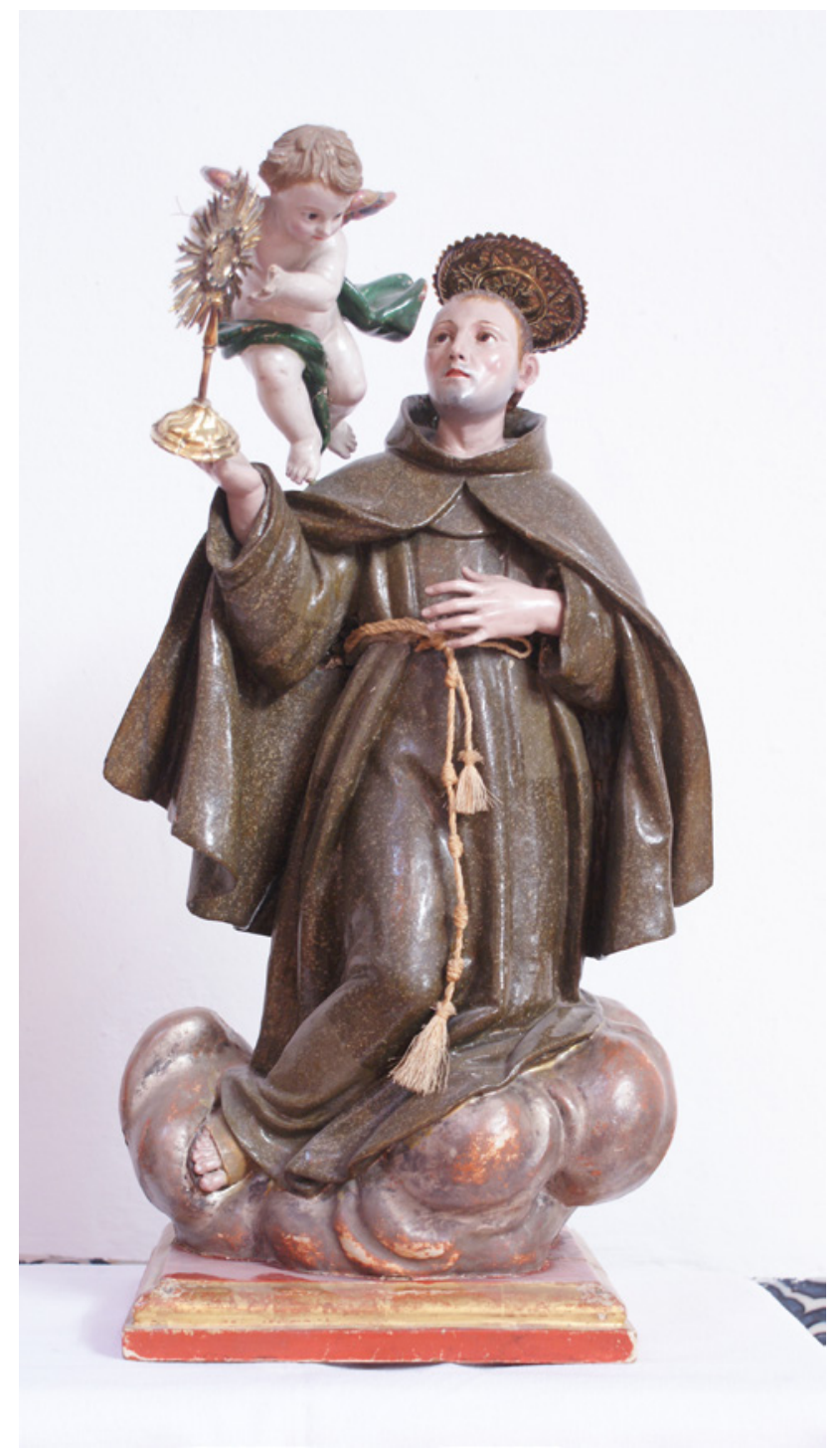

Figura 8. Escultura de San Pascual Bailón donada por don Miguel Ortega a la madre sor Margarita de la Natividad. Fotografía: Pedro Jaime Moreno de Soto. 